\title{
Investigation of gastrointestinal parasites of herbivores at Dhaka National Zoological Garden of Bangladesh
}

\author{
S. M. Rahman, A. R. Dey*, U. K. Kundu and N. Begum \\ Department of Parasitology, Faculty of Veterinary Science, Bangladesh Agricultural University, Mymensingh-2202, \\ Bangladesh, *E-mail: anitadey.dpp.vet@gmail.com
}

\begin{abstract}
A total of 52 fecal samples were collected from 21 herbivores at Dhaka zoo during January to May, 2012 to investigate the prevalence of gastrointestinal parasites of herbivores. Overall prevalence of parasitic infection was $76.9 \%$, of which $61.5 \%$ were positive for helminths and $55.8 \%$ were positive for protozoa. The identified parasites were Balantidium coli (55.8\%), Paramphistomum sp. (36.5\%), Fasciola sp. (19.2\%), stomach worm (3.9\%), Ascaris sp. $(1.9 \%)$ and Strongyloides sp. (1.9\%). Overall prevalence of mixed infection was $42.3 \%$. Mixed infection was observed in the animals such as Butani cattle (Balantidium coli and Paramphistomum sp.), Giraffe (Balantidium coli and Paramphistomum sp.), Spotted deer (Balantidium coli, Paramphistomum sp. and Fasciola sp.), Sambar deer (Balantidium coli and Fasciola sp.), Horse (Balantidium coli and Ascaris sp.), Greater kudu (Balantidium coli and Paramphistomum sp.), Nil gai (Balantidium coli and stomach worm), Black wilde beast (Balantidium coli and Paramphistomum sp.), Impala (Balantidium coli and Strongyloides sp.), Hippopotamus (Balantidium coli and Paramphistomum sp.), Zebra (Balantidium coli and Paramphistomum sp.), Wilde beast (Balantidium coli and Paramphistomum sp.; Balantidium coli and Paramphistomum sp. and Fasciola sp.), One Horned Rhinoceros (Balantidium coli and Paramphistomum sp.), Common Eland (Balantidium coli and Paramphistomum sp.), Oryx (Balantidium coli and stomach worm). Diameter of ova or cyst was also measured. Egg per gram/ Cyst per gram of feces (EPG/ CPG) were ranged from 300-1200. Gastrointestinal parasites are highly prevalent in herbivores of Dhaka zoo. Strategic control measure is necessary to protect the endangered species from parasitic infestation.
\end{abstract}

Keywords: Gastrointestinal parasites, Prevalence, Herbivores, Dhaka zoo

\section{Introduction}

Captivity of wildlife creates an unnatural system and disrupts the balance between parasite and host and it makes a stressful environment and become animals diseased or can even die from parasite loads that they would have survived under natural conditions (Van Wyk and Boomker, 2011). In nature, practically no animal is free from parasites. When the parasitized animal is brought from wild to captivity, despite quarantine measures, the new condition of zoos is generally unfavorable for the animal but favorable to the parasites. Occurrence of parasites in animals housed in zoo might vary according to the type of husbandry practices, disease prophylaxis and treatment administered. Usually, captive animals do not show alarming signs of parasitism if regular deworming practices carried out in the zoo (Parasani et al., 2001). Intensive husbandry of animals produces conditions which facilitates the spread of parasites. Parasitic diseases often represent a major concern in zoo animals for the high environmental contamination due to the maintenance of animals in confined areas. Moreover, anthelmintics resistance limits the control of parasites of zoo animals. Unfortunately, inadequate information on diseases and parasites of zoo animals is a major limiting factor in zoological gardens. Investigations on endoparasitic fauna are important for the study of the prevalence and geographical distribution (Zasityte and Grikienciene, 2002). There is no doubt that a regular program of gastrointestinal parasite surveillance and measures of control based on correct diagnosis, effective treatment and proper prophylaxis would certainly assist in reversing the situation of ill health in zoo animals. By trying to establish a profile of gastro-intestinal parasites among the zoo animal in Dhaka National Zoological Garden, Bangladesh, valuable information will be obtained for the development of public health and preventive medicine. Considering these facts, the present study was undertaken to determine the prevalence and intensity of gastrointestinal parasites and to study the morphometric characters of parasitic egg and cyst in different herbivores. 


\section{Materials and Methods}

\section{Study area}

The study was conducted in herbivores at Dhaka Zoo. Morphological identification of parasitic ova and other developmental stages of parasites were performed in the laboratory of the Department of Parasitology, Bangladesh Agricultural University, Mymensingh.

\section{Study period}

This investigation was carried out during the period from January to May, 2012.

\section{Selection of animals}

Fifty two samples were collected from different herbivores such as Impala, Nil gai, Gayal, Giraffe, Common Eland, Sambar deer, Maya deer, Spotted deer, Horse, Greater kudu, Hippopotamus, Chimpanzee, Black wilde beast, Water buck, Elephant, wilde beast, Butani cattle, Oryx, Zebra, one Horned Rhinoceros and Ass.

\section{Collection and preservation and shipment of samples}

Fecal samples were collected with the help of animal's caretakers in the early morning. Collected fecal sample were placed in a polythene bag containing $10 \%$ formalin and the opening edge of the bag was tightly closed with ribbon and marked according to species and brought it to the laboratory.

\section{Coprology examination}

Samples were examined and processed for microscopic examination. The ova or cysts of different parasites were identified as described by Soulsby (1982) and quantitative estimation was done by Stoll's ova counting technique to determine eggs per gram (EPG)/ cysts per gram (CPG) of feces.

\section{Stoll's ova dilution technique}

The fecal sample was first well mixed and then three grams of feces were weighed with the help of a balance and weight box and taken in $100 \mathrm{ml}$ graduated beaker, which was filled with $45 \mathrm{ml}$ water and thoroughly mixed with water by a magnetic stirrer. The mixture was then strained with a coffee strainer. The strained mixture was again shaken and $0.15 \mathrm{ml}$ of mixture was taken on to a glass slide and covered with a cover slip. Care was taken to avoid bubble formation. Then the slide was placed under a microscope and helminth eggs were identified and counted. The total number of eggs of parasites found in the slide was multiplied by 100 to get the eggs per grams of feces (EPG).

\section{Measurement the diameter of ova and cysts}

The length and width of identified eggs and cysts of different parasites in different animals were measured by a micrometer as described by Cable (1965).

\section{Results}

\section{Overall prevalence of gastrointestinal parasites in herbivores at Dhaka National Zoo}

A total of 52 fecal samples were examined and 40 samples were found to be infected with different types of parasite. At least one intestinal parasite was identified in the fecal samples of each of the animals except Chimpanzee. The overall prevalence of parasitic infection was $76.9 \%$ (40) where helminths and protozoan infection were $65.4 \%$ (34) and $55.8 \%$ (29), respectively (Fig.1). Identified parasites were protozoa (Balantidium coli), nematodes (Strongylus sp., Ascaris sp. and stomach worm) and trematode (Fasciola sp. and Paramphistomum sp.) (Fig. 2). Results indicated that helminths infection were more common than protozoan infection in herbivore animals (Fig.1). 


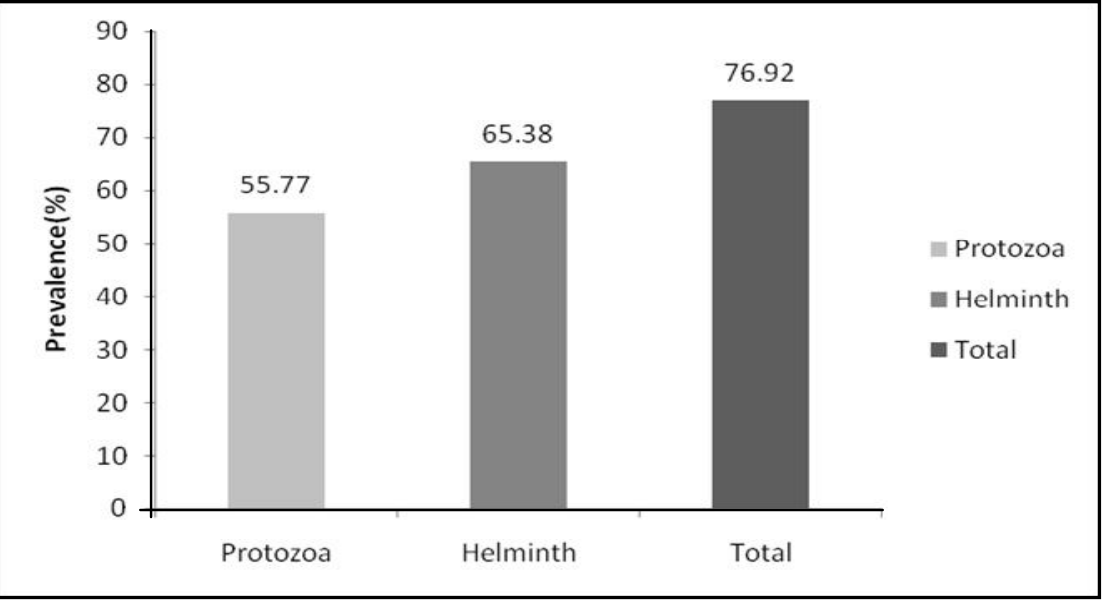

Fig. 1. Overall Prevalence of parasitic infection in herbivore animals at Dhaka Zoo

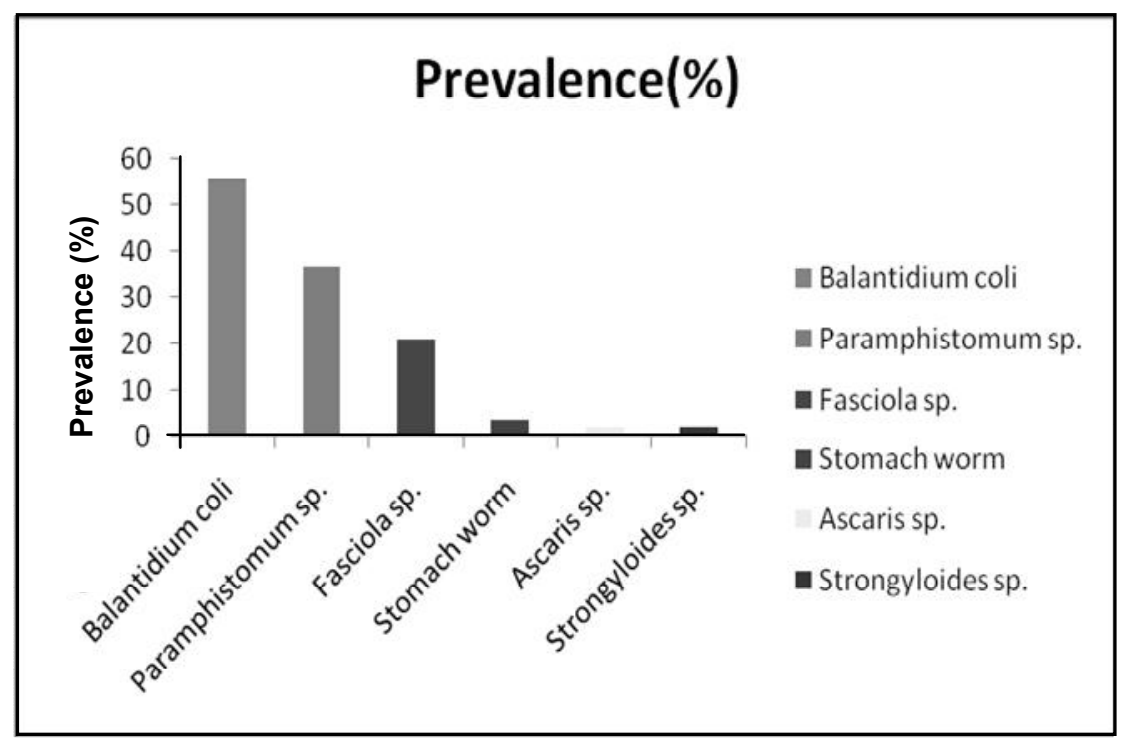

Fig. 2. Prevalence of different parasites in herbivores at Dhaka Zoo

\section{Prevalence and intensity of different gastrointestinal parasites in herbivores at Dhaka Zoo}

Identified parasites of herbivores were Balantidium coli (55.8\%), Paramphistomum sp. (36.5\%), Fasciola sp. $(21.2 \%)$, stomach worm (3.9\%), Ascaris sp. (1.9\%) and Strongyloides sp. (1.9\%) (Table 2). Intensity of different parasites in different animals was measured. The mean EPG /CPG were calculated of each of the animal and the ranges were shown in Table 1. The highest CPG (cysts per gram) of Balantidium coli was 700 in Zebra. The highest EPG (eggs per gram) of stomach worm (1200) was in Nil Gai. The intensity of other parasites was Paramphistomum sp. (700) in Water Buck, Fasciola sp. (500), Strongyloides sp. (200) in Impala and Ascaris sp. (300) in Horse.

\section{Prevalence of mixed infection}

Overall prevalence of mixed infection was $42.3 \%$. Mixed infection was observed in the fifteen animals such as Butani cattle, Giraffe, Spotted deer, Sambar deer, Horse, Greater kudu, Nil gai, Black wilde beast, Impala, Hippopotamus, Zebra, wilde beast, one Horned Rhinoceros, common Eland and Oryx. Prevalence of the examined mixed infection were Balantidium coli and Paramphistomum sp. (26.92\%); Balantidium coli and Fasciola sp. (5.8\%); Balantidium coli and stomach worm (3.9\%); Balantidium coli and Strongyloides sp. (0.02\%); Balantidium coli and Ascaris sp. (0.02\%); Paramphistomum sp., Fasciola sp. and Balantidium coli $(0.02 \%)$ (Table 3 ). 
Table 1. Name of parasites and intensity of ova/cyst of different parasites in different animals at Dhaka Zoo

\begin{tabular}{|c|c|c|c|c|}
\hline \multirow[t]{2}{*}{ Name of the animal } & \multirow[t]{2}{*}{ Name of the parasite } & \multirow[t]{2}{*}{$\begin{array}{l}\text { No. of positive case } \\
\text { (No. of sample) }\end{array}$} & \multirow[t]{2}{*}{$\begin{array}{c}\text { Prevalence } \\
(\%)\end{array}$} & $\begin{array}{c}\text { Intensity of infection } \\
\text { (EPG /CPG) }\end{array}$ \\
\hline & & & & Ranges \\
\hline \multirow{2}{*}{ Butani Cattle } & Paramphistomum sp. & $2(2)$ & 100 & $100-200$ \\
\hline & Balantidium coli & $2(2)$ & 100 & $100-400$ \\
\hline Asian Elephant & Balantidium coli & $1(2)$ & 50 & 400 \\
\hline \multirow[t]{2}{*}{ Giraffe } & Balantidium coli & $2(4)$ & 50 & $200-300$ \\
\hline & Paramphistomum sp. & $3(4)$ & 75 & $100-300$ \\
\hline \multirow[t]{2}{*}{ Greater Kudu } & Balantidium coli & $1(2)$ & 50 & 400 \\
\hline & $\begin{array}{l}\text { Paramphistomum sp. } \\
\text {. }\end{array}$ & $1(2)$ & 50 & 200 \\
\hline \multirow[t]{2}{*}{ Nil Gai } & Stomach worm & $1(2)$ & 50 & 1200 \\
\hline & \begin{tabular}{|l} 
Balantidium coli \\
\end{tabular} & 1(2) & 50 & 400 \\
\hline \multirow[t]{2}{*}{ Black Wilde Beast } & Balantidium coli & $2(2)$ & 100 & $100-300$ \\
\hline & Paramphistomum sp. & $1(2)$ & 50 & 200 \\
\hline Gayal & Paramphistomum sp. & $1(2)$ & 50 & 200 \\
\hline \multirow[t]{3}{*}{ Spotted deer } & Balantidium coli & $3(6)$ & 50 & $200-300$ \\
\hline & Paramphistomum sp. & $2(6)$ & 33.33 & $100-300$ \\
\hline & Fasciola sp. & $3(6)$ & 50 & $200-500$ \\
\hline \multirow[t]{2}{*}{ Sambar deer } & Balantidium coli & $3(4)$ & 75 & $100-300$ \\
\hline & Fasciola sp. & $3(4)$ & 75 & $200-400$ \\
\hline Water buck & Paramphistomum sp. & $1(2)$ & 50 & 700 \\
\hline \multirow[t]{2}{*}{ Impala } & Strongyloides sp. & $1(2)$ & 50 & $100-200$ \\
\hline & Balantidium coli & $2(2)$ & 100 & $100-400$ \\
\hline Barking Deer & Fasciola sp. & $3(4)$ & 75 & $100-300$ \\
\hline \multirow[t]{2}{*}{ Hippopotamus } & Balantidium coli & $2(2)$ & 100 & $100-400$ \\
\hline & Paramphistomum sp. & $2(2)$ & 100 & $100-200$ \\
\hline \multirow[t]{2}{*}{ Horse } & Ascaris sp. & $1(2)$ & 50 & 300 \\
\hline & Balantidium coli & 2(2) & 100 & $200-300$ \\
\hline Ass & Fasciola sp. & $1(2)$ & 50 & 100 \\
\hline \multirow[t]{2}{*}{ Zebra } & Balantidium coli & $1(2)$ & 50 & 700 \\
\hline & Paramphistomum sp. & $2(2)$ & 100 & $100-200$ \\
\hline Chimpanzee & Nil & $0(2)$ & & \\
\hline \multirow{2}{*}{$\begin{array}{l}\text { One Horned } \\
\text { Rhinoceros }\end{array}$} & Balantidium coli & $2(2)$ & 100 & $100-400$ \\
\hline & Paramphistomum sp. & $1(2)$ & 50 & 200 \\
\hline \multirow[t]{3}{*}{ Wilde Beast } & Balantidium coli & $2(2)$ & 100 & $200-400$ \\
\hline & Paramphistomum sp. & $2(2)$ & 100 & $200-300$ \\
\hline & \begin{tabular}{|l|} 
Fasciola sp. \\
\end{tabular} & $1(2)$ & 50 & 300 \\
\hline \multirow[t]{2}{*}{ Common Eland } & Paramphistomum sp. & $1(2)$ & 50 & 300 \\
\hline & Balantidium coli & $2(2)$ & 100 & $200-400$ \\
\hline \multirow[t]{2}{*}{ Oryx } & Stomach worm & $1(2)$ & 50 & 300 \\
\hline & \begin{tabular}{|l} 
Balantidium coli \\
\end{tabular} & 1(2) & 50 & 400 \\
\hline
\end{tabular}

Table 2. Prevalence of parasites in different herbivore animals at Dhaka zoo

\begin{tabular}{|l|l|c|c|}
\hline Types of parasites & Name of the parasites & No. of case & Prevalence (\%) \\
\hline Protozoa & Balantidium coli & 29 & 55.8 \\
\hline \multirow{3}{*}{ Trematode } & Paramphistomum sp. & 19 & 36.5 \\
\cline { 2 - 4 } & Fasciola sp. & 11 & 21.2 \\
\hline \multirow{3}{*}{ Nematode } & Stomach worm & 02 & 3.9 \\
\cline { 2 - 4 } & Ascaris sp. & 01 & 1.9 \\
\cline { 2 - 4 } & Strongyloides sp. & 01 & 1.9 \\
\hline
\end{tabular}

Table 3. Prevalence of mixed infection

\begin{tabular}{|c|c|c|}
\hline Name of the parasites & No. of case & Prevalence (\%) \\
\hline Balantidium coli and Paramphistomum sp. & 14 & 26.9 \\
\hline Balantidium coli and Fasciola sp & 03 & 5.8 \\
\hline Balantidium coli and Stomach worm & 02 & 3.9 \\
\hline Balantidium coli and Strongyloides sp. & 1 & 0.02 \\
\hline Balantidium coli and Ascaris sp. & 1 & 0.02 \\
\hline Paramphistomum sp., Fasciola sp. and Balantidium coli & 1 & 0.02 \\
\hline
\end{tabular}


Diameter of ova or cyst of different gastrointestinal parasites in different Zoo animals

The diameters (length by width) in $\mu \mathrm{m}$ of egg or cyst of different gastrointestinal parasites were measured in the present study. The diameter of Balantidium coli $(43.5-45 \times 29-35) \mu \mathrm{m}$, Paramphistomum sp. (160 - 170 x 90 - 95) $\mu \mathrm{m}$, Fasciola sp. $(87$ x 43.5) $\mu \mathrm{m}$, Ascaris sp. $(70$ x 50) $\mu \mathrm{m}$, stomach worm $(72.5 \times$ 43.5) $\mu \mathrm{m}$ and Strongyloides sp. $(58.0 \times 29.0) \mu \mathrm{m}$ in different zoo animals were calculated.

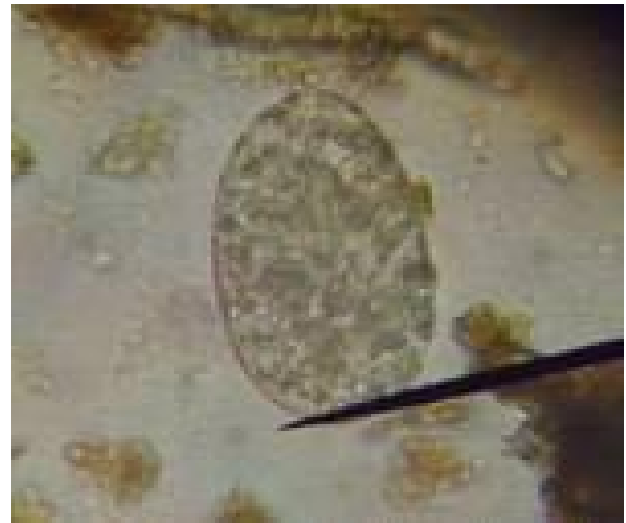

Plate 1. Egg of Fasciola sp. of Spotted deer (720X)

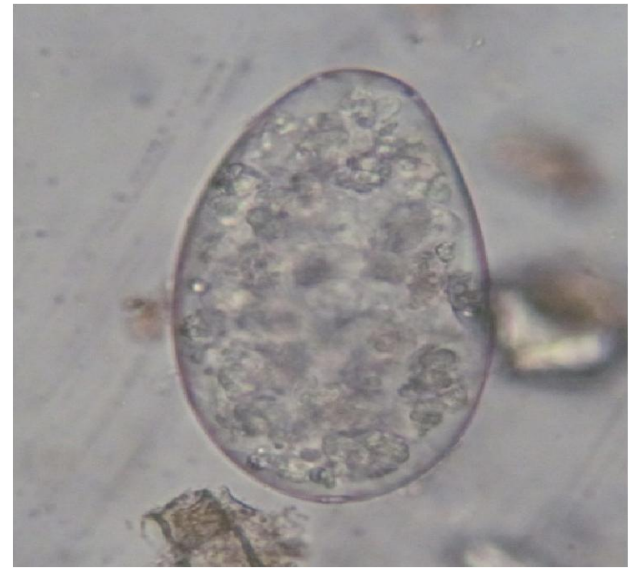

Plate 3. Egg of Paramphistomum sp. of Butani cattle (720X)

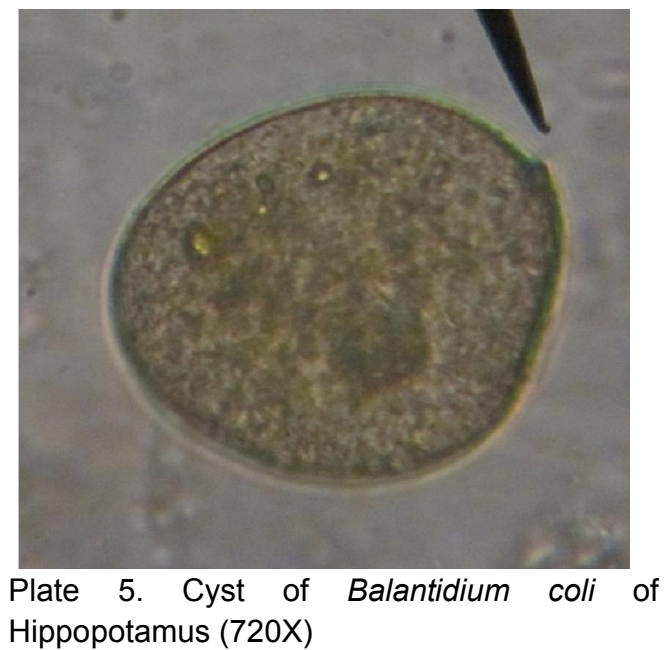

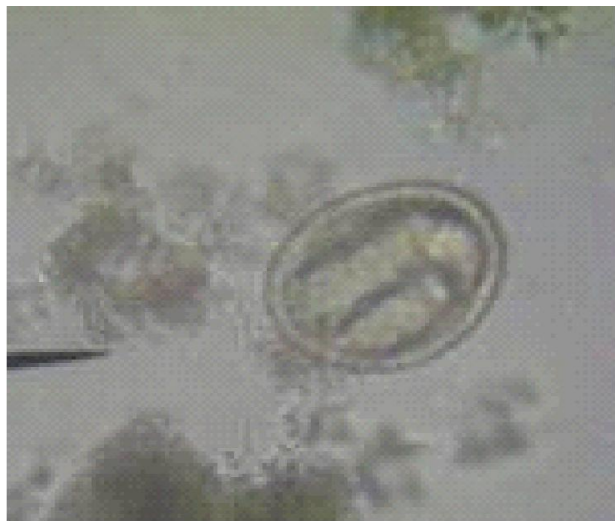

Plate 2. Egg of Strongyloides sp. of Impala (720X)

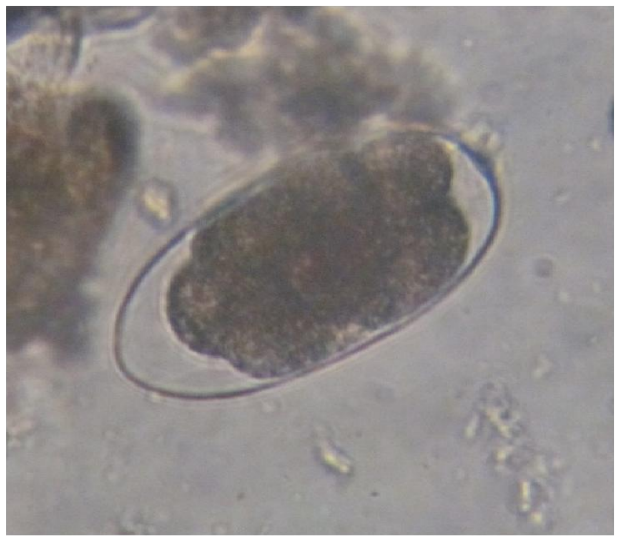

Plate 4. Egg of stomach worm of Oryx (720X)

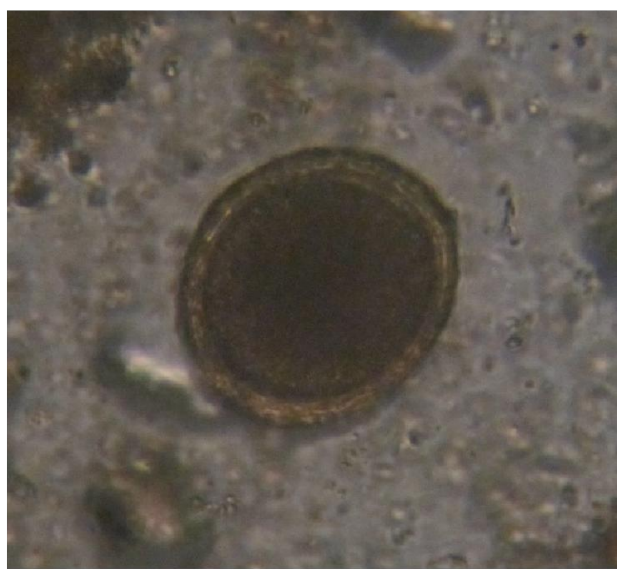

Plate 6. Egg of Ascaris sp. of Horse (720X) 


\section{Discussion}

Overall $76.9 \%$ of herbivore animals of Dhaka Zoo were found positive for gastrointestinal parasites, which is similar with the earlier reports of Opara et al., (2010) who revealed $76.6 \%$ positive cases. This finding is slightly higher than the report of Corden et al., (2008) who observed that the prevalence was $72.5 \%$. On the other hand, the lower prevalence rate than the present study was recorded as $60.7 \%$ by Parasani et al., (2001), 56.3\% by Lim et al., (2008), 48.1\% by Modi et al.,(1997), 42.4\% by Reddy et al., (1992) and $40.4 \%$ by Chakraborty and Islam (1996). This may be due to geographic conditions, husbandry practice and source of feeds of the animalwhich influences the prevalence.

The prevalence of helminths infection (65.4\%) was found higher than protozoan infection (55.8\%). This is similar with the report of Parasani et al., (2001) who revealed that $50 \%$ animal's positive for helminths infection and $18.8 \%$ for protozoa in Rajkot Municipal Corporation zoo. The present study also confirms the report of Varadharajan and Kandasamy (2000) who recorded that $58 \%$ animals were positive for helminths infections and $6 \%$ were positive for protozoan infections. On the other hand Opara et al., (2010) recorded the higher prevalence of helminths $(82.2 \%)$ than protozoa $(17.8 \%)$. The high occurrence of GIT helminthes which comprised more nematodes, agrees with Rossanigo and Gruner (1995). The high prevalence of helminths encountered in the survey explained by the existence of favorable climatic conditions which support prolonged survival of infective nematode larvae.

The intensity of different parasites in different herbivore animals was calculated and measured in this study. The mean EPG/CPG was not measured in most of the animal due to single sample and also the number of positive case was one or two. So, in case of more than one, the range of lowest and highest intensity was indicated. The intensity of different parasites was similar with the findings of Singh et al., (2009).

The results indicate that $55.8 \%$ of animals were infected with Balantidium coli followed by Paramphistomum sp. (36.5\%), Fasciola sp. (21.2\%), stomach worm (3.9\%), Ascaris sp. (1.9\%) and Strongyloides sp. (1.9\%). Ruta et al., (2009) found Strongyloides sp. (73.3\%) and Paramphistomum sp. $(63.0 \%)$ in red deer and fallow deer. Opara et al., (2010) observed Ascaris sp. and Fasciola sp. in different zoo animals. This difference might be due to location of animal cages, availability of intermediate host near the cages and the source of feeds. The probable cause of Fasciola sp. infection was strongly connected with mud snails that live on the edges of drain and act as intermediate host (Vengust, 2003). The cage of deer at Dhaka Zoo is located near the lake of Zoo. Another important probable cause was the green grasses and leaves supplied to deer used to take from outside of the Zoo which may be contaminated with metacercaria (Kanungo et al., 2010).

In this study, overall prevalence of mixed infection was $42.3 \%$. Mixed infection was observed in the fifteen animals such as butani cattle, giraffe, spotted deer, sambar deer, horse, greater kudu, nil gai, black wild beast, impala, hippopotamus, zebra, wild beast, one horned rhinoceros, common eland and oryx. Prevalence of mixed infection were Balantidium coli and Paramphistomum sp. (26.9\%); Balantidium coli and Fasciola sp. (5.8\%); Balantidium coli and stomach worm (3.9\%); Balantidium coli and Strongyloides sp. (0.02\%); Balantidium coli and Ascaris sp. (0.02\%); Paramphistomum sp., Fasciola sp. and Balantidium coli $(0.02 \%)$. The mixed infection in deer was recorded by Kanungo et al., (2010) and Mutani et al., (2003). This suggests that there is a fairly high rate of transmission of the parasites observed between individuals either because of the gregarious nature or because of suitable environmental conditions. The finding of mixed infection in this study might be due to presence of different aged animals in the same cages, feeding management and improper disposal of feces.

The diameter of egg or cyst of different gastrointestinal parasites found in the present study is almost similar with the findings of Hendrix and Robinson (2006), Christensen (1938) and Soulsby (1982). But sometimes differ from the present study e.g. the diameter of egg of Fasciola sp. $(87 \times 43.5 \mu \mathrm{m}$.) is

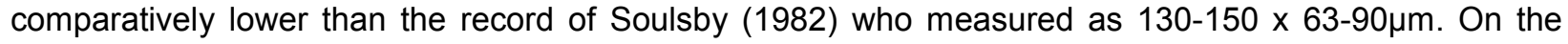
other hand, the result of present study revealed that the diameter of cyst of Balantidium coli was same in Deer and Hippopotamus $(43.5 \times 29.0 \mu \mathrm{m}$.). But Hendrix and Robinson (2006) indicated the diameter of cyst of Balantidium coli is $40-60 \mu \mathrm{m}$. This variation of size with the previous findings might be due to the method of measurement, strains of the parasite, species of the host and climatic factors. 
Rahman et al.

\section{Conclusion}

Gastrointestinal parasites are highly prevalent in herbivores of Dhaka Zoo. The present study provided a partial concept regarding parasitic infection of captive animals of Dhaka Zoo and also helps to find out the effective control measure, which is necessary to safeguard the health of Zoo animals.

\section{References}

Cable, M.R. 1965. An illustrated Laboratory Manual of Parasitology. $5^{\text {th }}$ edition, Burgress publishing company Minneapolis, USA. pp. 5-6.

Chakraborty, A. and Islam, S. 1996. A survey of gastrointestinal parasitic infection in some free ranging herbivores in the Kaziranga National Park. Zoos' Print 11: 3-5.

Christensen, J.F. 1938. Occurrence of coccidian Eimeria bukidnonensis in American cattle. Proceedings of the Helminthological Society of Washington. 5: 24.

Corden, P., Prados, G.H., Romero, A., Sanchez, M.S., Pontes, M., Osuna, A. and Rosales, M.J. 2008. Intestinal parasitism in the animals of the zoological garden "Peña Escrita" (Almuñecar, Spain). Veterinary Parasitology 156: 302-309.

Hendrix, M. and Robinson. 2006. Diagnostic Parasitology for Veterinary Technicians. $3^{\text {rd }}$ Edition. Mosby Elsevier, St. Louis,Missouri. 103:18-50.

Kanungo, S., Das, A., Das, G.M. and Shakif-ul-Azam. 2010. Prevalence of gastro-intestinal helminthiasis in captive deer of Bangladesh. Wayamba Journal of Animal Science 2: 42- 45.

Lim, Y.A.L., Ngui, R., Shukri, J., Rohela, M. and Mat, N.H.R. 2008. Intestinal parasites in various animals at a zoo in Malaysia. Veterinary Parasitology 157: 154-159.

Modi, G.S., Prasad, B.N. and Sinha, B.K. 1997. Seasonal effect on prevalence of parasitic zoonotic diseases among zoo animals of Bihar. Zoos' Print 12: 8-11.

Mutani, A., Kamara, R. and Gabriel, B. 2003. A preliminary investigation on the gastrointestinal helminths of the Barbados green monkey, Cercopithecus aethiops sabaeus. Revista do Institute de Medicina tropical SaoPaulo 45:193-195.

Opara, M.N., Osuji, C.T. and Opara, J.A. 2010. Gastrointestinal parasitism in captive animals at the zoological garden, Nekede Owerri, Southeast Nigeria. Report and Opinion 2:21-28.

Parasani, H.R., Momin, R.R., Maradin, M.G. and Veer, S. 2001. A survey of gastrointestinal parasites of captive animals at Rajkot munipical corporation zoo, Rajkot, Gujarat. Zoo's Print Journal 16(10):604-606.

Reddy, J.N.R., Jagannath, M.S., Souza, P.E.D. and Rahman, A.S. 1992. Prevalence of gastrointestinal parasites in mammals and captive birds at Bennaerghata National Park, Bangalore, India. Indian Journal of Animal Science 62: 1046-1048.

Rossanigo, C.E. and Gruner, L.. 1995. Moisture and temperature report and opinion requirements in feces for the development of free living stages of gastrointestinal nematodes of sheep and cattle and deer. Journal Helminthology 67: 357-362.

Ruta, M., Anna, K., Pēteris, K., Edgars, L., Dace, K., Evija, E., Daina, I.M.R., Krūklīte, A., Keidāns, P., Liepiņš, E., Keidāne, K., Eihvalde, E. and Ikauniece, D. 2009. Parasitic infestation of animals in deer gardens in Latvia. Acta Biologica universitatis Daugavpiliensis 9: $109-114$.

Singh, P.L.D., Gupta, M.P., Sharma, S. and Sharma, D.R. 2009. Epidemiology and chemotherapy of parasitic infections in wild omnivores in the Mechendra Choudhury Zoological park, Chhat Bir, Punjab. Journal of Threatened Texa 1:62-64.

Soulsby, E.J.L. 1982. Helminths, Arthopods and Protozoa of Domesticated Animals. $7^{\text {th }}$ Edition. Bailliere and Tindal, London. pp. 766-771.

VanWyk, I.C. and Boomker, J. 2011. Parasites of South African wildlife. XIX. The prevalence of helminths in some common antelopes, warthogs and a bushpig in the Limpopo province, South Africa', Onderstepoort Journal of Veterinary Research 78: 1-11.

Varadharajan, A. and Kandasamy, A. 2000. A survey of gastro-intestinal parasites of wild animals in captivity in the V.O.C. Park and Mini Zoo, Coimbatore. Zoos' Print Journal 15: 257-258.

Vengušt, G. 2003. Comparison of the parasitic fauna of fallow deer (Dama dama) from two enclosures in Slovenia. Slovenia, Veterinary Research 40: 27-31.

Zasityte, R. and Grikienciene, T. 2002. Some data in endoparasites of common mole in Lithnani, Act Zoological Lituanica 4: 403. 